\title{
Postharvest management of New Zealand flower thrips on export apricots using ethyl formate
}

\author{
S.P. Redpath, A. Wilson, L.E. Jamieson, N.E.M. Page-Weir, M.J. Griffin, A. Chhagan \\ and B. Hamilton \\ The New Zealand Institute for Plant \& Food Research Limited (Plant E Food Research), \\ Private Bag 92169, Auckland \\ Corresponding author: simon.redpath@plantandfood.co.nz
}

\begin{abstract}
New Zealand flower thrips (NZFT, Thrips obscuratus) is the most abundant pest on New Zealand apricots at harvest and is a quarantine pest for apricot export markets. Ethyl formate (EF) is a Generally Recognised As Safe (GRAS) compound being investigated as a postharvest fumigant. This study determined the efficacy of $\mathrm{EF}+\mathrm{CO}_{2}$ (Vapormate ${ }^{\mathrm{TM}}$ ) treatments against NZFT and their impact on apricot fruit quality in shipping containers. NZFT adults and larvae on apricots were treated in field bins of apricots in a $28.2 \mathrm{~m}^{3}$ refrigerated shipping container at $15^{\circ} \mathrm{C}$ for $1 \mathrm{~h}$ with $0.8-1.0 \% \mathrm{EF}+\mathrm{CO}_{2}$ or $1.0-1.2 \% \mathrm{EF}+\mathrm{CO}_{2}$ in Hawke's Bay and Central Otago, respectively. In Hawke's Bay the treatments resulted in $100 \%$ mortality of NZFT adults and larvae. In Central Otago, the treatments resulted in $100 \%$ mortality of NZFT adults and $98-100 \%$ larval mortality. Export grade apricot cultivars expressed no adverse effects on quality to this concentration of $\mathrm{EF}+\mathrm{CO}_{2}$.
\end{abstract}

Keywords New Zealand flower thrips, Thrips obscuratus, ethyl formate, apricots, disinfestation.

\section{INTRODUCTION}

New Zealand flower thrips (NZFT, Thrips obscuratus (Crawford)) are the most abundant pest species on apricot cultivars at harvest in New Zealand (Chhagan et al. 2013) and are an actionable quarantine pest for export markets including Australia, USA, UK and Europe. Disinfestation treatments are required to increase export volume and value, ensuring that fruit are free from quarantine pests, fruit quality is not reduced, and residue limits are not exceeded. Currently, carbaryl is sprayed on orchards to control thrips close to harvest. However, this method is increasingly unacceptable because of residue thresholds. Consequently, there is a need for reliable alternatives to control NZFT.
Ethyl formate (EF) is a Generally Recognised As Safe (GRAS) compound with pesticidal action (FDA 2006). Ethyl formate is used as a disinfestation treatment against a range of horticultural products, such as strawberries, sultanas, table grapes and dates (Simpson et al. 2004; Simpson et al. 2007; Tarr et al. 2007; Finkelman et al. 2010). It is available in New Zealand under the trade name Vapormate ${ }^{\mathrm{TM}}$ (16.7 wt $\%$ EF dissolved in liquid $\mathrm{CO}_{2}$ ).

Studies have been conducted over the past 2 years to determine NZFT mortality responses and apricot tolerance thresholds to $\mathrm{EF}+\mathrm{CO}_{2}$ (Chhagan et al. 2013). In Year 1 (2011), a mean lethal $\mathrm{EF}\left(+\mathrm{CO}_{2}\right)$ concentration of 0.16 or $0.24 \%$ 
was required to achieve $99 \%$ mortality $\left(\mathrm{LC}_{99}\right)$ of NZFT adults and larvae, respectively, for a 1 -h treatment at $21.7^{\circ} \mathrm{C}$ in a 250 -litre chamber. Treatments with mean EF concentrations of $0.30-1.14 \%$ and $0.28-1.03 \%+\mathrm{CO}_{2}$ for 1 and $2 \mathrm{~h}$ respectively, did not have negative impacts on apricot fruit quality.

In Year 2 (2012), trials in custom-built 76.8-litre chambers in the Volatile Treatment Facility (VTF) at Plant \& Food Research (PFR) in Auckland resulted in mean lethal $\mathrm{EF}+\mathrm{CO}_{2}$ concentrations of $0.48,0.78$ and $0.47 \%$ to achieve 99\% mortality $\left(\mathrm{LC}_{99}\right)$ of NZFT adults, and mean lethal $\mathrm{EF}+\mathrm{CO}_{2}$ concentrations of $0.51,0.68$ and $0.40 \%$ to achieve $\mathrm{LC}_{99}$ of NZFT larvae in 1 -h treatments at 5,15 and $25^{\circ} \mathrm{C}$, respectively (Chhagan et al. 2013). The quality of apricots treated with mean EF concentrations of 0.54$1.7 \%+\mathrm{CO}_{2}$ at $15^{\circ} \mathrm{C}$ for $1 \mathrm{~h}$ was not affected. $\mathrm{EF}$ breaks down quickly into ethanol and formic acid (Desmarchelier et al. 1999) and is exempt from residue limits when applied as a postharvest fumigant (MPI 2013). In the presence of apricots $72-73 \%$ EF degraded over a 1-h fumigation, boxes degraded $40-42 \% \mathrm{EF}$, and a combination of fruit and boxes degraded $74-77 \% \mathrm{EF}$, compared with that in empty chambers.

EF degradation rates in the presence of various fruits and packaging differ considerably (Leesch et al. 2008; De Lima 2009; De Lima 2010). Generally fruit degrades EF at a higher rate than packaging (Chhagan et al. 2013). Greater breakdown of EF in the presence of commodities and packaging will tend to express lower concentration $\times$ time products when exposed to single shot $\mathrm{EF}+\mathrm{CO}_{2}$ fumigations. Concentration $\times$ time product $(\mathrm{Ct})^{2}$ is widely used to establish mortality thresholds for target pests in fumigation trials (Damcevski \& Annis 2006; Xin et al. 2008).

This paper presents the results of research conducted in Year 3, where the aim was to determine the efficacy of $\mathrm{EF}+\mathrm{CO}_{2}$ (applied as Vapormate $^{\mathrm{TM}}$ ) against NZFT at a commercial scale in refrigerated shipping containers.

\section{MATERIALS AND METHODS}

In November 2013 (Hawke's Bay) and January 2014 (Central Otago), trials were conducted to investigate the efficacy of Vapormate ${ }^{\mathrm{TM}}$ against
NZFT within a $28.2 \mathrm{~m}^{3}$ commercially available refrigerated shipping container with fruit held at approximately $15^{\circ} \mathrm{C}$.

\section{Insect and fruit supply}

Flax flowers (Phormium sp.) with adult and larval NZFT were collected from Auckland into fine mesh fabric bags 1-3 days before treatments and held at ambient laboratory temperature until treatment. Unsprayed apricots ('Royal Rosa') were sourced from a commercial orchard in Hawke's Bay and the PFR research orchard in Central Otago ('Clutha Gold'). Apricots were picked 0-2 days before treatment and washed to remove naturally infested NZFT.

\section{Experimental setup}

The day before each treatment, 100 adult NZFT (approximately 50:50 male and female) were transferred from the flax flowers using a fine tipped paintbrush onto three apricots with a small amount of bulrush (Typha orientalis) pollen inside a plastic insect-proof container (10 $\mathrm{cm}$ high, $10.5 \mathrm{~cm}$ diameter at the top and $8.5 \mathrm{~cm}$ diameter at the bottom) vented with fine wire gauze at either end. Parafilm ${ }^{\bigotimes}$ provided an additional seal around the edge of the lid of the container preventing insects from escaping. Each container represented one replicate.

Similarly, NZFT larvae were transferred from flax flowers and caged on apricots (two cages per fruit, 10 larvae per cage $=20$ larvae per fruit). Both first and second instar larvae were used, to ensure a range of sizes in each cage. Cages were oval in shape and approximately $2.8 \times 3.5 \mathrm{~cm}$ diameter, $1 \mathrm{~cm}$ high with the top surface covered with fine mesh gauze. Each cage was securely attached to the cheek of an apricot using Blu$\mathrm{Tak}^{\bigotimes}$. Five fruit for each replicate were placed together in an open plastic basket.

Ten replicate groups of NZFT adult and larval NZFT per treatment were placed within apricot plastic crates in the shipping container. Three further replicates were kept at ambient temperature in the laboratory and used as controls.

NZFT containers were placed at high, medium and low locations within crates/bins on a pallet in the container and at the outer edge and middle of 
the pallet within each location. After treatment insects were held at ambient temperature until assessment the next day.

\section{Treatments}

Based on the results from previous work (Chhagan et al. 2013), NZFT and apricots were exposed to $\mathrm{EF}+\mathrm{CO}_{2}$ (Vapormate ${ }^{\mathrm{TM}}$ ) at $1 \%$ for 1 and $2 \mathrm{~h}$ and $0.8 \%$ for 1 and $2 \mathrm{~h}$ in Hawke's Bay (four treatments); and $1 \% \mathrm{EF}+\mathrm{CO}_{2}$ (Vapormate $^{\mathrm{TM}}$ ) for $1 \mathrm{~h}$ (three treatments) and $1.2 \%$ for $1 \mathrm{~h}$ (one treatment) in Central Otago (Table 1). EF concentrations were calculated based on the area of an empty fumigation container. Temperatures inside the refrigerated shipping container set at $15^{\circ} \mathrm{C}$ were ca $17^{\circ} \mathrm{C}$ in Hawke's Bay and ca $13^{\circ} \mathrm{C}$ in Central Otago. The untreated controls were held at ca $20^{\circ} \mathrm{C}$.

Treatments were carried out in a commerciallyavailable refrigerated shipping container $(5.4 \times$ $2.3 \times 2.0 \mathrm{~m}, 28.2 \mathrm{~m}^{3}$ ) set at $15^{\circ} \mathrm{C}$. Vapormate ${ }^{\mathrm{TM}}$ was applied via a vaporiser set at $110^{\circ} \mathrm{C}$ (supplied by BOC Gases) into the shipping container at calculated rates $(0.8,1$ or $1.2 \% \mathrm{EF})$ based on an empty container volume.

In Hawke's Bay, an adequate number of apricots could not be obtained to fill the shipping container; therefore apples were used as a proxy for apricots to simulate the degree of loading that would occur commercially. Eight pallets of fruit were loaded into the container for the two $1 \%$ EF treatments: four pallets of boxed apples at the back, two pallets of plastic crates with apricots and apples of alternating layers (nine layers) and two pallets of boxed apples at the front (load factor based on external dimensions of the boxes/ crates was $68 \%$ ). For the two $0.8 \%$ EF treatments, four pallets of boxed apples at the back and one pallet of apricots (six layers) in the middle and no pallets of apples at the front of the container (load factor based on external dimensions of the boxes/crates was 39\%). The same four pallets of apples were used in the back of the container because preliminary trials conducted in VTF chambers found repeated applications of EF to the same apples did not affect concentration of $\mathrm{EF}$ in later treatments.
In Central Otago, the shipping container was filled with five rows of bins. The back two rows consisted of processing bins $(1.6 \times 1.1 \times 0.75 \mathrm{~m})$ stacked two high. The next two rows consisted of orchard bins $(1.3 \times 1.0 \times 0.38 \mathrm{~m})$ stacked four high and the last row, at the front of the container, consisted of processing bins stacked two high (load factor based on external dimensions of the bins was $42 \%$ ). Bins with apricots that were not being used for fruit quality assessments were reused in subsequent treatments.

Along with the injection port (placed high on the side wall), there were two other sampling tubes placed on the side walls at medium and low heights. These three tubes were sampled alternately at regular intervals during the treatment using a GfG microtector II G460, which gave a reading for both $\mathrm{EF} \%$ and $\mathrm{CO}_{2} \%$. The three sampling regions within the container were averaged to give a final concentration of both gases at a given time. Calculation of the concentration $\times$ time $(\mathrm{Ct})$ product involved measuring the area under the EF exposure curve (Leesch et al. 2008).

Twelve temperature probes fitted to a squirrel logger (Grant 2020 series, UK) were placed at low, medium and high locations throughout the container and temperatures logged. The temperature of control replicates was also logged. The shipping container was sealed with PVC tape to minimise leaks.

\section{Assessment}

Treated and untreated NZFT were held at ambient temperature and assessed $24 \mathrm{~h}$ after treatment under a $10-50 \times$ stereo binocular microscope. Numbers of live and dead adults and larvae/pupae were recorded. Apricots exposed to adults potentially had eggs, therefore adults were removed and apricots were stored for an additional $7-14$ days at $\sim 20^{\circ} \mathrm{C}$ to determine the viability of any eggs laid.

\section{RESULTS}

Mortality of both adult and larval New Zealand flower thrips was $100 \%$ across all treatments in Hawke's Bay. Treatments in Central Otago killed 
$100 \%$ of adults and from 98.4 to $100 \%$ of larvae. Mortality of adults and larvae in the control replicates varied from $3.2 \% \pm 0.02$ to $27.1 \% \pm 0.04$ (Table 1). In Hawke's Bay 4446 adults were placed on to apricots and no viable eggs were detected on treated or untreated apricots (no larvae emerged from eggs recorded on apricots 1 week after treatment). In Central Otago 777 and 2938 adults were placed on control and treatment apricots, respectively. At 9-14 days after treatment 23 and 27 thrips, were recorded as emerged from eggs that were laid on control and treated apricots, respectively. Statistical analysis was not required to determine significance of differences between the percentage mortality of treated and untreated NZFT, because the differences were so large.

EF concentrations decreased more rapidly over time in Central Otago than in Hawke's Bay trials. The EF concentration recorded for one of the $1 \%$ EF treatments in Central Otago increased after the first reading; this was because an inadequate

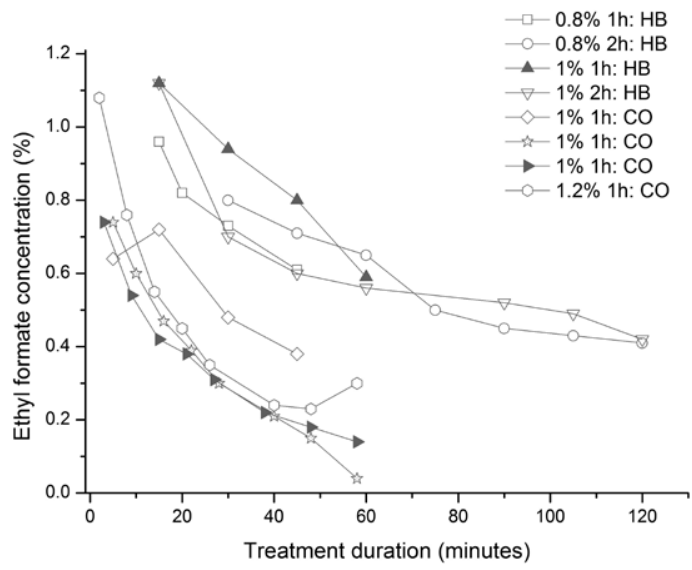

Figure 1 Actual measured ethyl formate concentrations (\%) at a medium height within a refrigerated shipping container during fumigation treatments targeting Thrips obscuratus on apricot fruit in Hawke's Bay (HB) and Central Otago (CO).

Table 1 Percentage mortality of adult and larval Thrips obscuratus after fumigation with actual doses of $0.72-1.18 \%$ ethyl formate $(\mathrm{EF})+\mathrm{CO}_{2}$ for 1 or $2 \mathrm{~h}$ on apricot fruit in refrigerated shipping containers in Hawke's Bay (HB) and Central Otago (CO) in 2013/14.

\begin{tabular}{|c|c|c|c|c|c|c|c|}
\hline & & & & Larvae & & Adults & \\
\hline $\begin{array}{l}\text { Calculated } \\
\text { EF (\%) }\end{array}$ & Location & $\begin{array}{l}\text { Time } \\
\text { (h) }\end{array}$ & & $\begin{array}{c}\text { Mean mortality } \\
(\% \pm S E)\end{array}$ & $\mathrm{n}$ & $\begin{array}{c}\text { Mean mortality } \\
(\% \pm S E)\end{array}$ & $\mathrm{n}$ \\
\hline \multirow[t]{2}{*}{1} & $\mathrm{HB}$ & 1 & Control & $17.5 \pm 0.05$ & 92 & $9.7 \pm 0.00$ & 228 \\
\hline & & & Treated & $100 \pm 0.00$ & 493 & $100 \pm 0.00$ & 879 \\
\hline \multirow[t]{2}{*}{1} & $\mathrm{HB}$ & 2 & Control & $11.7 \pm 0.04$ & 135 & $3.2 \pm 0.02$ & 224 \\
\hline & & & Treated & $100 \pm 0.00$ & 515 & $100 \pm 0.00$ & 878 \\
\hline \multirow[t]{2}{*}{0.8} & $\mathrm{HB}$ & 1 & Control & $6.3 \pm 0.02$ & 120 & $7.3 \pm 0.04$ & 239 \\
\hline & & & Treated & $100 \pm 0.00$ & 499 & $100 \pm 0.00$ & 893 \\
\hline \multirow[t]{2}{*}{0.8} & $\mathrm{HB}$ & 2 & Control & $12.17 \pm 0.07$ & 83 & $9.3 \pm 0.04$ & 260 \\
\hline & & & Treated & $100 \pm 0.00$ & 493 & $100 \pm 0.00$ & 845 \\
\hline \multirow[t]{2}{*}{1} & $\mathrm{CO}$ & 1 & Control & $27.1 \pm 0.04$ & 244 & $6.0 \pm 0.03$ & 265 \\
\hline & & & Treated & $98.4 \pm 0.00$ & 850 & $100 \pm 0.00$ & 892 \\
\hline \multirow[t]{2}{*}{1} & $\mathrm{CO}$ & 1 & Control & $7.8 \pm 0.01$ & 236 & $3.1 \pm 0.01$ & 239 \\
\hline & & & Treated & $100 \pm 0.00$ & 828 & $100 \pm 0.00$ & 1111 \\
\hline \multirow[t]{2}{*}{1} & $\mathrm{CO}$ & 1 & Control & $17.9 \pm 0.05$ & 231 & $3.5 \pm 0.01$ & 273 \\
\hline & & & Treated & $99.6 \pm 0.00$ & 836 & $100 \pm 0.00$ & 935 \\
\hline \multirow[t]{2}{*}{1.2} & $\mathrm{CO}$ & 1 & Control & $4.0 \pm 0.01$ & 325 & Not treated & \\
\hline & & & Treated & $99.9 \pm 0.00$ & 911 & Not treated & \\
\hline
\end{tabular}


amount of Vapormate ${ }^{\mathrm{TM}}$ was initially dispensed (Figure 1). Overall the EF Ct product available for controlling NZFT was higher in Hawke's Bay (0.8-1.33) than in Central Otago (0.35-0.53).

\section{DISCUSSION}

$\mathrm{EF}+\mathrm{CO}_{2} \quad$ Vapormate $^{\mathrm{TM}}$ ) is a promising postharvest treatment to control NZFT on apricots in New Zealand. Chhagan et al. (2013) found that an effective EF treatment to control $99 \%$ of adults and larval NZFT was 0.68 and $0.78 \%$ EF for $1 \mathrm{~h}$, respectively (concentration $\times$ time (Ct) products of 0.68 and 0.78 , respectively). In the present experiment, Cts from the four Hawke's Bay treatments ranged from $0.8 \%$ to $1.33 \%$, which is above that required for NZFT control. However, Cts from the four Central Otago treatments ranged from 0.35 to 0.53 , below the target Ct but still high enough to kill all adults and $99.5 \%$ of larvae. This may have been because of the different rates of EF breakdown rates due to the types of fruit (apples versus apricots) loaded into the shipping container in Hawke's Bay and Central Otago, and the different fruit containers (boxes and crates versus orchard bins) and shipping containers used at each site. Chhagan et al. (2013) found that $72-73 \%$ of EF was degraded in the presence of apricots over a 1-h treatment. Preliminary trials at PFR also indicate that $15 \%$ EF was degraded in the presence of apples, indicating that more EF will need to be applied to loads of apricots to maintain an effective concentration for NZFT control. This highlights the importance of standardising EF application methods to ensure repeatability of the treatment (similar Cts). The most practical way to achieve this for commercial operations will be to maintain EF at a set range by topping up regardless of load type and amount; this will ensure that there is enough EF available for pest kill.

The survival of $0.05 \%$ of NZFT larvae in Central Otago could be attributed to several factors, the most obvious being the low $\mathrm{Ct}$ (0.350.53 ) achieved at that site. Another explanation could be larvae hiding under Blu-Tak ${ }^{\otimes}$, where a sealed pocket may have formed. The thigmotactic behaviour of NZFT may have resulted in their potentially being covered by $\mathrm{Blu}^{-\mathrm{Tak}^{\otimes}}$ when a fruit/cage was bumped or moved. It was clear that NZFT lay very low numbers of eggs on apricots (24 viable eggs recorded from 1728 adults in controls). However, $\mathrm{EF}+\mathrm{CO}_{2}$ did not eliminate egg hatch (27 viable eggs recorded from 6433 adults in treatments).

Export-grade apricot cultivars expressed no adverse effects to $1-1.2 \% \mathrm{EF}\left(+\mathrm{CO}_{2}\right)$ applied as a single shot. Moreover, the $\mathrm{EF}+\mathrm{CO}_{2}$ treated fruit showed less damage than untreated fruit. This is probably because of the elevated concentrations of $\mathrm{CO}_{2}$ during treatment. A small-scale sensory test discovered no differences between the taste of treated and untreated fruit (R. Feng, Plant \& Food Research, unpublished data).

Further research is required to confirm that commercial treatments using Vapormate $^{\mathrm{TM}}$ maintained between 0.8 and $1 \%$ EF consistently reduce the risk of live NZFT being detected on export apricots. Additionally, to increase the flexibility of when a Vapormate ${ }^{\mathrm{TM}}$ treatment can be applied without breaking the coolchain, it would be prudent to investigate the use of Vapormate $^{\mathrm{TM}}$ applied at lower temperatures to packed product.

\section{ACKNOWLEDGEMENTS}

The authors would like to thank Earnscy Weaver and Chris Hale from Summerfruit New Zealand. Thanks also to Roger Brownlie and Ian Nicholls for the supply of fruit and assisting with the trials in Hawke's Bay and Central Otago. A special mention goes to Kate Colhoun, Bernie Attfield and Tara Taylor for technical assistance.

\section{REFERENCES}

Chhagan A, Jamieson LE, Griffin MJ, PageWeir NEM, Poulton J, Zulhendri F, Feng R, Connolly PG, Davis VA, Olsson S, Redpath SP, Kean AM, Woolf AB 2013. Postharvest management of New Zealand flower thrips (Thrips obscuratus) on apricots using ethyl formate or pyrethrum-based treatments. New Zealand Plant Protection 66: 63-74

Damcevski KA, Annis PC 2006. Influence of grain and relative humidity on the mortality of Sitophilus oryzae (L.) adults exposed to ethyl formate vapour. Journal of Stored Products Research 42: 61-74. 
De Lima C 2009. Fumigation of table grapes using ethyl formate + carbon dioxide as a quarantine treatment. Department of Agriculture and Food, Western Australia. 53 p.

De Lima C 2010. Fumigation trials of citrus using ethyl formate + carbon dioxide as a quarantine treatment. Department of Agiculture and Food, Western Australia. 34 p.

Desmarchelier JM, Johnston FM, le Trang V 1999. Ethyl formate, formic acid and ethanol in air, wheat, barley and sultanas: analysis of natural levels and fumigant residues. Pesticide Science 55: 815-824.

FDAU2006.GRASSubstances(SCOGS)Database. http://www.fda.gov/Food/FoodIngredients Packaging/GenerallyRecognizedasSafeGRAS/ GRASSubstancesSCOGSDatabase/default. htm (accessed 20 April 2014).

Finkelman S, Lendler E, Navarro S, Navarro H, Ashbell G 2010. New prospects for ethyl formate as a fumigant for the date industry. 10th International Working Conference on Stored Product Protection. 27 June-July 2010, Estoril, Portugal. Julius Kühn-Institut, Berlin, Germany (http://pub.jki.bund.de/index.php/ JKA/issue/view/719). Pp. 359-364.

Leesch JG, Smilanick JL, Tebbets JS 2008. Methyl bromide fumigation of packed table grapes: Effect of shipping box on gas concentrations and phytotoxicity. Postharvest Biology and Technology 49: 283-286.
MPI 2013. New Zealand (Maximum Residue Limits of Agricultural Compounds) Food Standards 2013. http://www.foodsafety. govt.nz/elibrary/industry/mrl-agriculturalcompounds-amdt-2013.pdf (accessed 20 April 2014).

Simpson T, Bikoba V, Mitcham EJ 2004. Effects of ethyl formate on fruit quality and target pest mortality for harvest strawberries. Postharvest Biology and Technology 34: 313319.

Simpson T, Bikoba V, Tipping C, Mitcham EJ 2007. Ethyl formate as a postharvest fumigant for selected pests of table grapes. Journal of Economic Entomology 100: 1084-1090.

Tarr CR, Reuss R, Clingeleffer PR, Annis PC 2007. The use of ethyl formate for space fumigation of dried vine fruit. Proceedings of an International Conference on Controlled Atmosphere and Fumigation in Stored Products. Gold-Coast, Australia. 8-13August 2004. FTIC Ltd. Publishing, Israel. Pp. 193205.

Xin N, Ren YL, Forrester RI, Ming X, Mahon D 2008. Toxicity of ethyl formate to adult Sitophilus oryzae (L.), Tribolium castaneum (herbst) and Rhyzopertha dominica (F.). Journal of Stored Products Research 44: 241246. 